\title{
Determinación geodésica del deslizamiento de falla para el terremoto de Lorca del 11 de Mayo de 2011 usando interferometría radar y GPS
}

\author{
PABlo J. GONZÁlez ${ }^{1}$, Kristy F. TIAMPO ${ }^{1}$, Mimmo PALANO ${ }^{2}$, Flavio CANNAVO ${ }^{2}$ \\ \& JOSÉ FERNÁNDEZ ${ }^{3}$ \\ ${ }^{1}$ Department of Earth Sciences / Western University, Canadá \\ ${ }^{2}$ Osservatorio Etneo - Sezione di Catania / Istituto Nazionale di Geofisica e Vulcanologia, Italia \\ ${ }^{3}$ Instituto de Geociencias / CSIC-UCM, España \\ pabloj.glez@gmail.com
}

Recibido: 01/05/2012

Aceptado: 25/09/2012

\begin{abstract}
Resumen
La falla de Alhama de Murcia (FAM) está compuesta por diferentes segmentos con movimiento de desgarre siniestral con componente inversa. La FAM es una de las fallas de mayor longitud en las Béticas (sudeste de España). Así, en las últimas décadas su potencial sismogenético se ha evaluado usando principalmente datos de paleo-sismicidad. El 11 de mayo de 2011 un terremoto de magnitud momento moderada (Mw 5.1) sacudió Lorca, causando nueve muertes y cuantiosos daños materiales. La localización inicial de la secuencia de replicas no sugería ninguna tendencia en particular. Por otro lado, inspecciones geológicas realizadas in situ no identificaron ninguna fractura superficial que se pudiera asociar a deformación cosísmica. Para poder mejorar la evaluación del peligro sísmico en la zona, es necesario localizar y, si es posible, caracterizar la distribución del deslizamiento en la falla que generó este terremoto.

En este trabajo presentamos deformaciones corticales pequeñas, pero significativas, medidas en la zona epicentral del terremoto de Lorca mediante el uso de técnicas geodésicas (interferometría radar de satélite y GPS). Los datos radar se procesaron obteniendo un conjunto de interferogramas diferenciales (corregidos por un hundimiento continuado debido a extracción de agua subterránea). Se han obtenido estimaciones GPS de coordenadas tanto diarias como a altas frecuencias $(1-\mathrm{Hz})$. Hemos realizado una inversión conjunta de los desplazamientos cosísmicos detectados con ambas técnicas para determinar los parámetros del plano de falla, considerando un modelo de dislocación rectangular en un semiespacio elástico. El plano de falla ajustado sigue la geometría estimada geológicamente para la FAM (orientación NE-SW y buzamiento de $\sim 70^{\circ} \mathrm{NW}$ ). Posteriormente, a partir del modelo con deslizamiento homogéneo obtenido, el plano de falla se extiende y divide en segmentos, permitiendo un análisis más detallado del patrón de distribución de deslizamiento sobre el plano de falla.

La distribución de deslizamiento obtenida indica que este ocurrió en un segmento principal de unos 4$5 \mathrm{~km}$ de longitud con movimiento inverso y siniestral (con una magnitud máxima de deslizamiento de $\sim 20 \mathrm{~cm}$ ). El modelado también indica que una parte del deslizamiento ocurrió cerca de la superficie bajo la zona central y suroeste de la ciudad de Lorca. El carácter somero del deslizamiento a lo largo del plano de falla, así como el efecto amplificador producido por la finalización de la ruptura bajo el sudoeste de la ciudad probablemente fue el causante de la relativamente alta intensidad de la aceleración registrada $(\sim 0.4 \mathrm{~g})$. Esta ha sido la primera vez que se ha detectado claramente deformación cosísmica producida por un terremoto en la Península Ibérica mediante el uso de técnicas geodésicas modernas (InSAR y GPS), y permitiendo invertir de forma rigurosa las características del terremoto.
\end{abstract}


Palabras clave: Terremoto de Lorca, modelo de salto cosísmico, GPS, interferometría radar, SO Beticas.

\title{
A geodetic coseismic fault-slip model for the May, 11th 2011 Lorca earthquake using radar interferometry and GPS
}

\begin{abstract}
The Alhama de Murcia Fault (AMF) is a compound multi-segmented oblique left-lateral fault system. The AMF is one the longest faults in the Eastern Betics Shear zone (Southeastern Spain). In the last decades its seismogenic potential has been carefully evaluated based on paleoseismological data. On May 11th, 2011 a moderate (Mw 5.1) earthquake shook the region, causing nine casualties and severe damage in Lorca city (Murcia region). The early reported location of the aftershock sequence did not draw any particular trend; furthermore in-situ geology surveys did not identify any surface coseismic slip-related ground deformation. In order to provide better seismic hazard assessments, we need to locate and, if possible, characterize the fault-slip distribution that generated this earthquake.

In this work, we detected small but significant ground deformation close to the epicentral area of the Lorca earthquake by using geodetic (satellite radar interferometry and GPS) data. Geodetic data was processed by using a stack of differential radar interferograms (corrected for a known long-term subsidence contribution), daily GPS estimated coordinates and high-rate 1-Hz GPS data. We jointly inverted the detected static coseismic displacements for the fault plane geometry parameters by using a rectangular dislocation model embedded in a homogeneous elastic half-space. The best-fitting fault plane closely follows the geologically derived AMF geometry (NE-SW strike trend and dipping $\sim 70^{\circ}$ to NW). Later, the obtained model geometry was extended and divided into patches to allow for a detailed analysis of the fault slip distribution pattern.

Slip distribution indicates that slip occurred in a main patch $-4-5 \mathrm{~km}$ long- with reverse and leftlateral motion (with peak fault slip magnitude of $\sim 20 \mathrm{~cm}$ ). However, the modelling results also indicate that fault slip occurred close to the surface along the centre and southwest of the city of Lorca. The shallower character of the slip and the effect of a finite dynamic rupture fault arrest probably caused the relatively intense ground acceleration recorded in the city of Lorca $(\sim 0.4 \mathrm{~g})$ and increased the building damage. This study also represents the first modern geodetically observed ground deformation signature due to seismic activity in the Iberian Peninsula.
\end{abstract}

Keywords: Lorca earthquake, geodetic coseismic model, GPS, radar interferometry, SE Betics.

Sumario: Introducción. 1. Sismo-tectónica regional. 2. Análisis y procesado de datos geodésicos. 2.1. Procesado GPS. 2.2. Procesado InSAR. 3. Modelo de dislocación. 3.1. Inversión no-lineal: Estimación de la geometría de la falla. 3.2. Inversión lineal: Distribución de deslizamiento. 4. Modelo de variación de esfuerzos cosísmicos. 5. Discusión y conclusiones. Agradecimientos. Referencias bibliográficas.

\section{Referencia normalizada}

González P.J. et al., (2012). Determinación geodésica del deslizamiento de falla para el terremoto de Lorca del 11 de Mayo de 2011 usando interferometría radar y GPS. Física de la Tierra, Vol. 24, 171-192.

\section{Introducción}

El 11 de Mayo de 2011 (16:47:13 UTC), un terremoto de magnitud momento moderada $(\mathrm{Mw}=5.1)$ sacudió la ciudad de Lorca en Murcia, España, una ciudad de unos 90000 habitantes (Fig. 1a). El terremoto principal causo grandes daños y un gran número de personas se vieron afectadas, provocando cientos de heridos y nueve fallecidos. Este terremoto fue precedido dos horas antes por un evento de magnitud 4.5, y seguido de cientos de replicas. Hasta el momento, los informes 
preliminares estiman los daños en aproximadamente 70 millones de euros. Alrededor de un $57 \%$ de las edificaciones se vieron afectadas, dejando miles de personas sin hogar. El epicentro, según el Instituto Geográfico Nacional (IGN), se localizó a unos 2 kilómetros al este-noreste de Lorca (Fig. 1b). Las soluciones preliminares de los mecanismos focales indican que una falla con orientación NE-SO con movimiento siniestroso e inverso, o una falla NO-SE con movimiento dextroso e inverso rompió durante el terremoto a una profundidad muy somera $(1-4 \mathrm{~km})$. Las localizaciones oficiales accesibles a través del catálogo público del IGN no definen ninguna orientación reconocible y muestra una gran dispersión al Este de Lorca (IGN, 2011). Sin embargo, las fallas reconocidas con métodos geológicos indicaban que la fuente sísmica más probable podía ser el plano NE-SO (Martínez-Díaz et al., 2011; Vissers and Meijninger, 2011). Estudios de directividad de la energía sísmica liberada y una refinada relocalización de la serie han confirmado que la falla responsable fue la falla de Alhama de Murcia, FAM (Rueda et al., 2011; López-Comino et al., 2012).

En este estudio, usamos los datos geodésicos disponibles, en concreto provenientes de interferometría radar diferencial y GPS, para estimar las características de la fuente sísmica y la distribución del salto/deslizamiento de falla cosísmico. La solución del mapa de deslizamiento cosísmico posee gran detalle (elementos de $\sim 500 \mathrm{~m}$ ). La solución preferida demuestra que existe un ligero reparto del deslizamiento en el plano de falla. Usando este modelo de deslizamiento distribuido calculamos un modelo de transferencia de esfuerzos para investigar el efecto que el movimiento cosísmico ha inducido en el área circundante. Así, en este trabajo se ha detectado deformación cosísmica claramente producida por un terremoto, por primera vez, en la Península Ibérica mediante el uso de técnicas geodésicas modernas (InSAR y GPS), permitiendo invertir de forma rigurosa las características del terremoto. El modelo de deslizamiento/salto de falla usando métodos geodésicos puede ser de gran importancia para complementar los análisis de datos sísmicos, y mejorar la evaluación del riesgo sísmico en esta región.

\section{Sismo-tectónica regional}

En zonas de convergencia rápida, la deformación se suele acomodar en zonas (o sistemas) de falla relativamente restringidas, con un movimiento relativo rápido y tiempos de recurrencia entre terremotos cortos. En el sureste de España, la tasa de convergencia de las placas litosféricas de Nubia (África) e Iberia (Eurasia) se produce con una tasa modesta, $\sim 4.1 \mathrm{~mm} / \mathrm{año}$, a lo largo de un límite de placas difuso (Palano et al., 2012). La convergencia se reparte en numerosas estructuras de deformación definiendo un escenario muy complejo para el análisis del potencial sísmico de esas estructuras.

En la última década, tanto datos geológicos como cartografías de detalle, y análisis paleosísmicos, han arrojado más luz sobre la actividad y potencial sismogenético de las mayores fallas del sureste de España (Fig. 1a). Sin embargo, debido a que sus tasas de movimiento son sub-milimétricas, muchas estructuras siguen 
estando sin cuantificar, por lo que son necesarios más estudios para definir su peligrosidad (Martínez-Díaz, 2002; Martínez-Díaz et al., 2003; Masana et al., 2004).
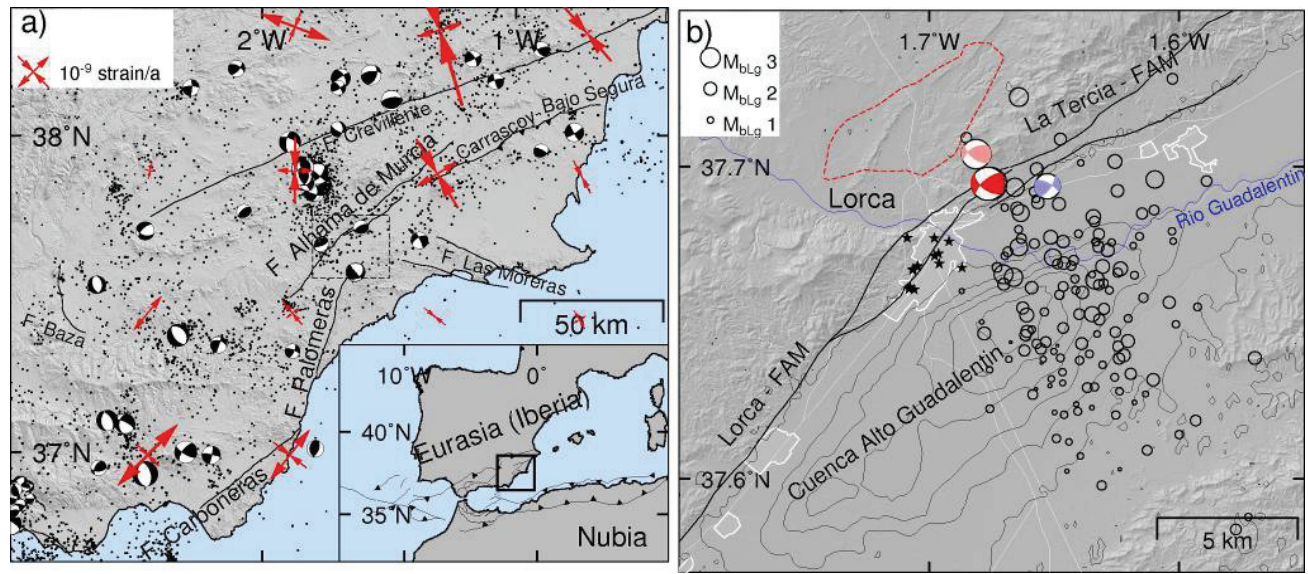

Fig 1a.- Modelo digital de elevaciones sombreado del sureste de España mostrando mecanismos focales (varias fuentes entre 1970-2010), y aspas rojas mostrando el campo de deformación finita instantánea calculado a partir de datos de velocidades de estaciones GPS (Palano et al., 2012). Los puntos negros muestran los terremotos localizados entre 2000 y 2010 según el IGN. Se muestra una selección de las principales fallas con sus respectivos nombres. El rectángulo negro con línea discontinua muestra la localización de la Fig. 1b. Recuadro inferior izquierdo: Localización de la zona de estudio en el contexto de la zona de convergencia Nubia-Eurasia. b) Modelo digital de elevaciones sombreado del entorno de Lorca mostrando: los mecanismos focales del terremoto principal (rojo), previo (rojo claro) y la mayor replica (azul claro) y el resto de réplicas (cículos, www.ign.es). La estrellas negras señalan las zonas con daños identificados por The International Disaster Charter (http://www.emergencyresponse.eu/gmes/en/event/Earthquake-in-Spain_109.html), localización aproximada de fallas cartografiadas previamente (Martínez-Díaz et al., 2003), las zonas urbanas (polígono gris con contorno blanco) y carreteras (líneas blancas). La zona irregular roja delimita la zona de sismicidad relocalizada según López-Comino et al. (2012). Las líneas de contorno marcan la subsidencia entre 1992-2007 (González and Fernández, 2011a)

La sismicidad moderada en esta zona de las Béticas no se alinea claramente con las trazas de las mayores fallas en superficie (Fig. 1a). Los mecanismos focales disponibles indican un régimen de esfuerzos complejo con predominancia del fallamiento inverso con cierta componente de desgarre, existiendo también una componente de fallamiento normal minoritaria (Fig. 1a).

Estas observaciones son consistentes con los datos más recientes de deformación superficial obtenidos con el análisis de datos GPS y su inversión para obtener el campo de velocidad de deformación finita, indicando acortamiento NNE-SSW de 
$\sim 2-3 \times 10^{-9}$ radianes y $\sim 1 \times 10^{-9}$ radianes de extensión en la dirección WNW-ESE (Fig. 1a) (Palano et al., 2012). Sin embargo, los resultados del análisis de las redes GPS son muy dispersos para cuantificar adecuadamente las tasas de deslizamiento de fallas individuales.

El sistema de fallas de Alhama de Murcia (FAM) es una estructura con expresión geomorfológica de unos $\sim 80 \mathrm{~km}$ de longitud. La tasa de deformación que acomoda la FAM se ha estimado en 0.07-0.6 mm/año de deslizamiento neto promedio durante los últimos $30 \mathrm{ka}$ (Masana et al., 2004). Durante los últimos 500 años, FAM ha generado 18 terremotos significativos con intensidades MSK $\geq$ VI. La ruptura previa más reciente asociada a FAM originó el terremoto de Lorca del 6 de Junio de 1977, Mb 4.2 (Mezcua et al., 1984). Sin embargo, este evento es de una magnitud muy pequeña para haber liberado una cantidad significativa de energía elástica. Así pues, el último terremoto similar al de 2011 cerca de Lorca ocurrió en 1818 (MSK VII). Asumiendo que hubiera liberado una porción muy significativa de la energía elástica acumulada, y teniendo en cuenta los valores máximos de tasas de deformación (Masana et al., 2004), como mínimo, y con una falla totalmente acoplada elásticamente, el déficit de deslizamiento acumulado sería de $\sim 12 \mathrm{~cm}$.

\section{Análisis y procesado de datos geodésicos}

\subsection{Procesado GPS}

En este trabajo hemos analizado datos GPS de estaciones de registro continuo, que cubren el periodo 2006.00-2011.67, adquiridos por diferentes redes geodésicas instaladas en el SE de España: Red ERGPS- IGN, Red RAP-Junta de Andalucia, Red Meristemum-Murcia, Red REGAM-Murcia y Red ERVA-Comunidad Valenciana. Para detalles técnicos véase Palano et al. (2012). Para procesar los datos hemos usado dos estrategias diferentes. En la primera estrategia, se ha procesado el conjunto de datos diarios con muestreo a $30 \mathrm{~s}$, usando el programa GAMIT-GLOBK (Herring et al., 2009), para caracterizar el patrón de la deformación de largo periodo de la zona de estudio. Como segunda estrategia, se procesaron datos de alta frecuencia para la detección de desplazamientos cosísmicos, cubriendo varios días en torno a la ocurrencia del terremoto, aplicando el método de posicionamiento GPS instantáneo (King and Bock, 2004).

Los datos diarios GPS se han procesado siguiendo el procedimiento descrito por Palano et al. (2011) para obtener soluciones diarias sin constreñimientos. Para mejorar la configuración global de la red y fijar las medidas regionales a un sistema de referencia externo, se introdujeron en el procesado datos de 11 estaciones IGS en registro continuo (ALAC, ALME, BRUS, CAGL, GRAS, GRAZ, MADR, MAS1, MATE, VILL and ZIMM). Usando el módulo GLORG de GLOBK se combinaron todas las soluciones diarias y sus covarianzas completas para estimar las posiciones y velocidades medias para cada estación en un sistema de referencia con la placa Euroasiática fija (Fig. 2a). 

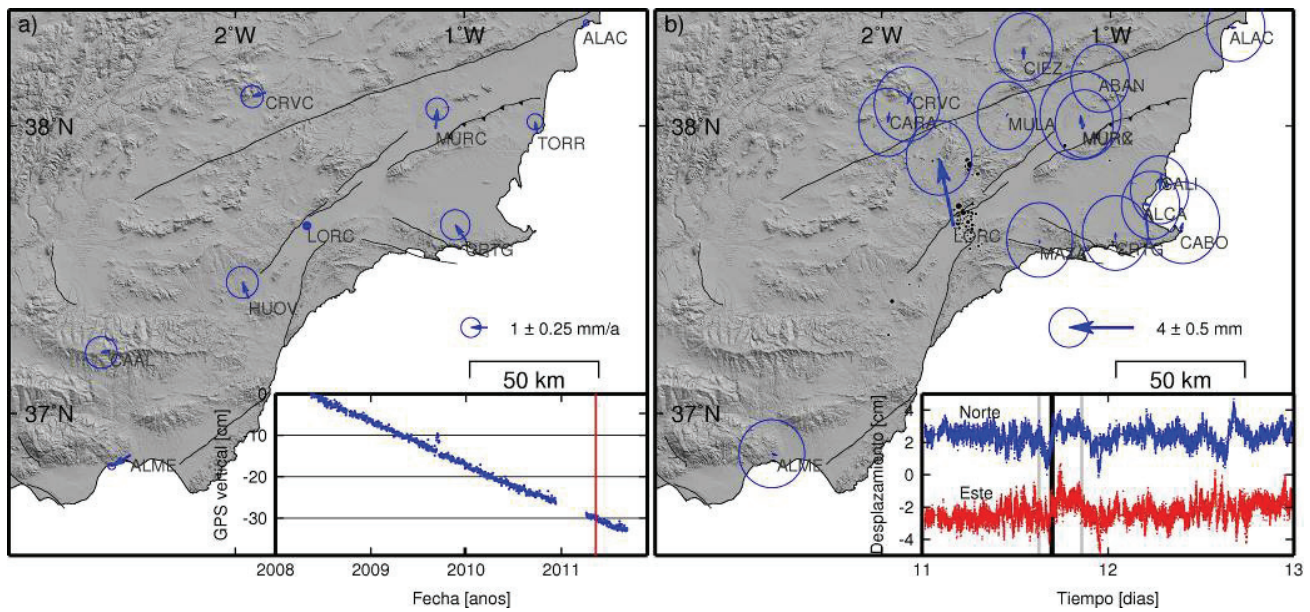

Fig. 2. a) Campo de velocidades GPS de largo periodo para la zona estudiada en un sistema de referencia con la placa Euroasiática fija (Palano et al., 2012). La estación LORC no se utiliza en este análisis ya que está afectada por un importante hundimiento relacionado con la extracción de agua (González and Fernández, 2011b) (ver recuadro en la zona inferior derecha del panel, donde la línea roja indica el terremoto de 11 de mayo de 2011), mostrando por tanto movimientos muy diferentes con respecto a todas las estaciones próximas. b) Desplazamientos cosísmicos en todas las estaciones de la zona producidos por el terremoto del 11 de mayo de 2011. El recuadro inferior muestra las componentes Norte y Este determinadas con observaciones a 1-Hz para la estación LORC: se observa la deformación transitoria asociada con la fase pre-, cosísmica (la línea vertical negra indica la ocurrencia del terremoto) o postsísmica temprana, pero sin mostrar valores claramente significativos.

Mediante la metodología de Beavan and Haines (2001) hemos calculado el tensor de velocidad de deformación finita 2D en el área estudiada. Esto se realiza interpolando el campo de velocidades GPS observadas y la información sobre sus covarianzas en una malla rectangular, con un espaciado de $40 \mathrm{~km}$. Para ello se utilizó un método de interpolación bicúbica con funciones spline. Finalmente, calculamos el tensor promedio 2D de velocidad de deformación finita como la derivada espacial de las velocidades en el centro de cada una de las celdas de la malla. La Fig. 1a muestra los resultados de deformación finita horizontal en la zona de estudio (indicadas por aspas de tamaño proporcional a la magnitud de la deformación). Posteriormente, podremos analizar la consistencia de la distribución de dislocación en la falla con respecto al campo de velocidad de deformación finita horizontal. La estación LORC no se utilizó en este análisis cinemático debido a que esta estación está afectada por un importante hundimiento asociado a la extracción de agua subterránea (González and Fernández, 2011b).

En concreto, en la estación LORC la tasa de hundimiento anual es bastante estable, con un valor de $\sim 10 \mathrm{~cm} /$ año (recuadro inferior en Fig. 2a), un resultado consis- 
tente con los obtenidos de un análisis InSAR entre 1992-2007 (González and Fernández, 2011b).

Para calcular la magnitud del desplazamiento cosísmico 3D hemos estimado las posiciones medias de las estaciones los 3 días anteriores y los 3 días posteriores al evento, aplicando constreñimientos internos mínimos (i.e., constriñendo variaciones por translación, escala y rotación, a $0.5 \mathrm{~mm}$ ). Los resultados indican que todas las estaciones, salvo LORC, permanecieron estables durante el terremoto. La estación LORC se desplazó $0.9 \pm 0.8 \mathrm{~mm}$ hacia el Oeste y $4.2 \pm 0.8 \mathrm{~mm}$ hacia el Norte (Fig. 2b). La componente vertical del desplazamiento cosísmico en esta estación no fue estadísticamente significativa, $2.3 \pm 3.3 \mathrm{~mm}$.

Para estudiar la posibilidad de la ocurrencia de deformaciones transitorias, se han analizado los datos GPS con la máxima frecuencia de muestreo posible (HighRate GPS, HRGPS) para la estación más próxima al epicentro (LORC $\sim 4 \mathrm{~km}$ ). Para el procesado HRGPS se usa el módulo Track del programa GAMIT/GLOBK (King and Bock, 2004; Herring et al., 2009), con órbitas precisas suministradas por el IGS (International GNSS Service, http://igscb.jpl.nasa.gov). Procesamos, a intervalos de 1 segundo, LORC como estación libre, eligiendo como estaciones de referencia dos estaciones diferentes MULA y CRVC elegidas por su proximidad a LORC. La serie temporal obtenida, para las tres componentes, no muestra ninguna característica relevante relacionada con la ocurrencia del terremoto, aunque se intento reducir el ruido producido por multipath filtrando las soluciones cinemáticas con un filtro sidéreo (Choi et al., 2004). Por tanto, los resultados no muestran ninguna deformación transitoria significativa (recuadro inferior en la Fig. 2b) asociada con las fases presísmica, cosísmica o post-sísmica temprana.

\subsection{Procesado InSAR}

Usamos imágenes radar de dos pasos orbitales descendentes diferentes del satélite ENVISAT de la Agencia Europea del Espacio (ESA), adquiridas durante el periodo Noviembre 2010 - Julio 2011. Se dispone de dos imágenes radar del paso orbital 209 con un ángulo de incidencia de 37 grados (modo I6), y cinco imágenes radar del paso orbital 008 con un ángulo de incidencia de 21 grados (modo I2) (Tabla 1 y Fig. 3). Calculamos interferogramas diferenciales (tamaño de píxel de $80 \mathrm{~m}$ ) usando los programas ROI_PAC, para focalizar los datos brutos (Rosen et al., 2004), y DORIS, para el análisis interferométrico (Kampes et al., 2003). Finalmente, la fase diferencial se desenrolla con el programa SNAPHU (Chen and Zebker, 2002).

Debido a que sólo contamos con dos imágenes disponibles del paso orbital 209 se obtuvo un único interferograma diferencial, que se muestra en la Fig 3a. En él, pese al ruido de fase, se puede identificar la señal cosísmica con una forma aproximadamente circular cubriendo un área que se desplaza hacia el satélite. Para los datos obtenidos del paso orbital 008 se realizó un procesado en serie temporal de la fase diferencial desenrollada de cada interferograma (González and Fernández, 2011a). No se aplicó ningún filtrado temporal para evitar sesgos provocados por la naturaleza de salto temporal de los desplazamientos cosísmicos. 
Tabla. 1. Información sobre las imágenes dato SAR utilizados en este trabajo. Ambas trazas orbitales son descendentes. Bperp denota la línea de base perpendicular en metros con respecto a la primera época.

\begin{tabular}{|c|c|c|c|}
\hline Datos & $\begin{array}{c}\text { Paso } \\
\text { orbital }\end{array}$ & $\begin{array}{c}\text { Fecha } \\
\text { [aaaammdd] }\end{array}$ & $\begin{array}{c}\text { Bperp } \\
{[\mathrm{m}]}\end{array}$ \\
\hline ENVISAT - I6 & 209 & 20110510 & 0 \\
\hline ENVISAT - I6 & 209 & 20110609 & -61 \\
\hline ENVISAT - I2 & 008 & 20101127 & 0 \\
\hline ENVISAT - I2 & 008 & 20110426 & -273 \\
\hline ENVISAT - I2 & 008 & 20110526 & -81 \\
\hline ENVISAT - I2 & 008 & 20110625 & -307 \\
\hline ENVISAT - I2 & 008 & 20110725 & -58 \\
\hline
\end{tabular}
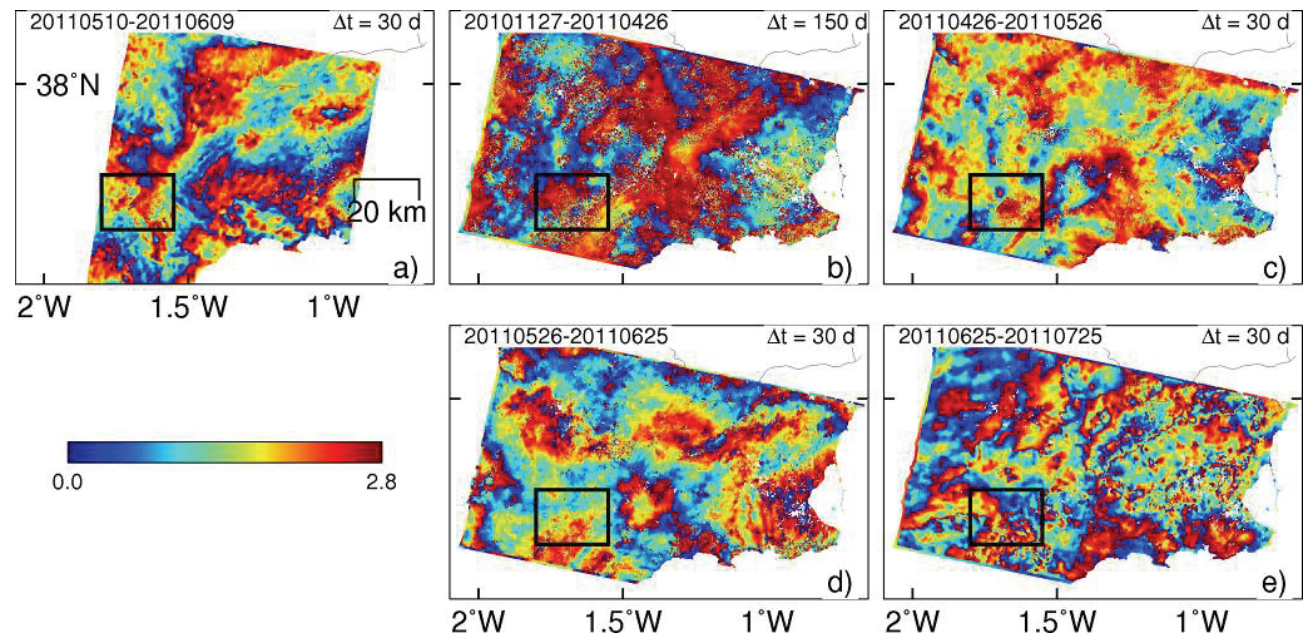

Fig. 3. a) Desplazamientos LOS del terreno determinados en banda $C(\sim 2.8 \mathrm{~cm})$ para las imágenes 10 Mayo 2011 - 9 Junio 2011 del satélite ENVISAT (traza 209, modo I6) usando un único interferograma diferencial. Se muestran también los desplazamientos LOS del terreno determinados usando un estudio de serie temporal con las imágenes de ENVISAT (traza 008, modo I2; ver Tabla 1) para los intervalos temporales b) 27 Noviembre 2010 - 26 Abril 2011, c) 26 Abril 2011 - 26 Mayo 2011, d) 26 Mayo 2011 - 25 Junio 2011, y e) 25 Junio 2011 - 25 Julio 2011. En cada panel se indica el periodo temporal y se marca con un rectángulo negro la zona de Lorca.

La Fig. 3b-e muestra diferentes periodos de la serie temporal de desplazamientos en la dirección del satélite (line-of-sight, LOS). En la figura Fig. 3b, se observan casi 2 ciclos (fringes) de deformación en la zona interior de la Cuenca del Alto Guadalentín. Esta es la máxima separación temporal diferencial (150 días) entre dos pasos consecutivos. Estos resultados son esperables considerando el hundimiento de 
largo periodo por extracción de agua subterránea previamente descrito (Fig. 2a). En la Fig. 3c se puede observar la deformación cosísmica. Principalmente se detecta una zona con movimiento hacia el satélite al norte de Lorca. También se detecta una zona que se aleja del satélite similar al área de máxima deformación provocado por el hundimiento de largo periodo. Finalmente, en las Fig 3d and 3e, no se observa ninguna deformación post-sísmica clara, y probablemente parte del patrón de variación de fase pueda atribuirse al hundimiento por compactación del acuífero.

En la Fig. 4 se muestran los resultados en el periodo cosísmico para los pasos orbitales 008 (Fig. 4a-c) y 209 (Fig. 4d-f). Como mencionamos previamente, y de acuerdo con los resultados InSAR del periodo 1992-2007, en la cuenca del Alto Guadalentín se registran tasas de hundimiento extremadamente altas, de hasta 15 cm/año (González and Fernández, 2011b). El análisis GPS del periodo 2006-2011 indica que la deformación continua con tasas de hundimiento relativamente constantes de unos $10 \mathrm{~cm} /$ año en la componente vertical de la estación LORC (Palano et al., 2012). Considerando el mecanismo focal estimado (con un movimiento inverso significativo), la deformación vertical elástica cosísmica en el bloque de muro ( hundimiento) aparecerá sumada al hundimiento de largo periodo producido por la extracción de agua. Esto puede sesgar el modelado e interpretación tectónica de los interferogramas. Por lo tanto, para corregir por este efecto calculamos un modelo de velocidad lineal promedio anual de hundimiento usando los datos InSAR previos (González and Fernández, 2011b). Este se obtiene ajustando un modelo lineal a la serie temporal de cada píxel (1992-2007). Debido a que la localización de los píxeles en ambos análisis no coincide, se interpola espacialmente usando un algoritmo de vecino más próximo para las localizaciones de los puntos coherentes de los resultados cosísmicos (Fig. 3). Luego, se escala al intervalo temporal de cada interferograma, 30 días en ambos interferogramas cosísmicos. Esta contribución de hundimiento (Fig. 4b y 4e) se resta de los interferogramas originales (Fig. 4a y 4d). Durante la corrección se tuvo en cuenta la diferencia entre las direcciones LOS para los diferentes pasos orbitales considerados (diferentes ángulos de incidencia). El efecto de la diferencia angular se corrige aplicando una función coseno. En las Fig. $4 \mathrm{c}$ y $4 \mathrm{f}$, se muestran los residuos - interferogramas corregidos por hundimiento.

\section{Modelo de dislocación}

Suponemos que la deformación cortical observada (Fig. 4) es debida al deslizamiento cosísmico tectónico en un segmento de falla a lo largo o muy cerca del sistema FAM. Este deslizamiento de falla puede ser aproximado como el efecto en superficie de un modelo de dislocación de cizalla rectangular (Okada, 1985). Así, hemos modelado la deformación dejando libre el movimiento en la dirección de cabeceo a lo largo de un plano de ruptura dentro de un semiespacio elástico homogéneo e isótropo y con coeficiente de Poisson de $v=0,25$. Obtenemos el conjunto de parámetros del modelo de dislocación óptimo usando un conjunto de tres datos geodésicos: i) los datos de ENVISAT descendente-I2, del paso orbital 008, ii) los 
datos de ENVISAT descendente-I6, del paso orbital 209, y iii) desplazamientos estáticos estimados con datos GPS de las estaciones cercanas (Fig. 2b).
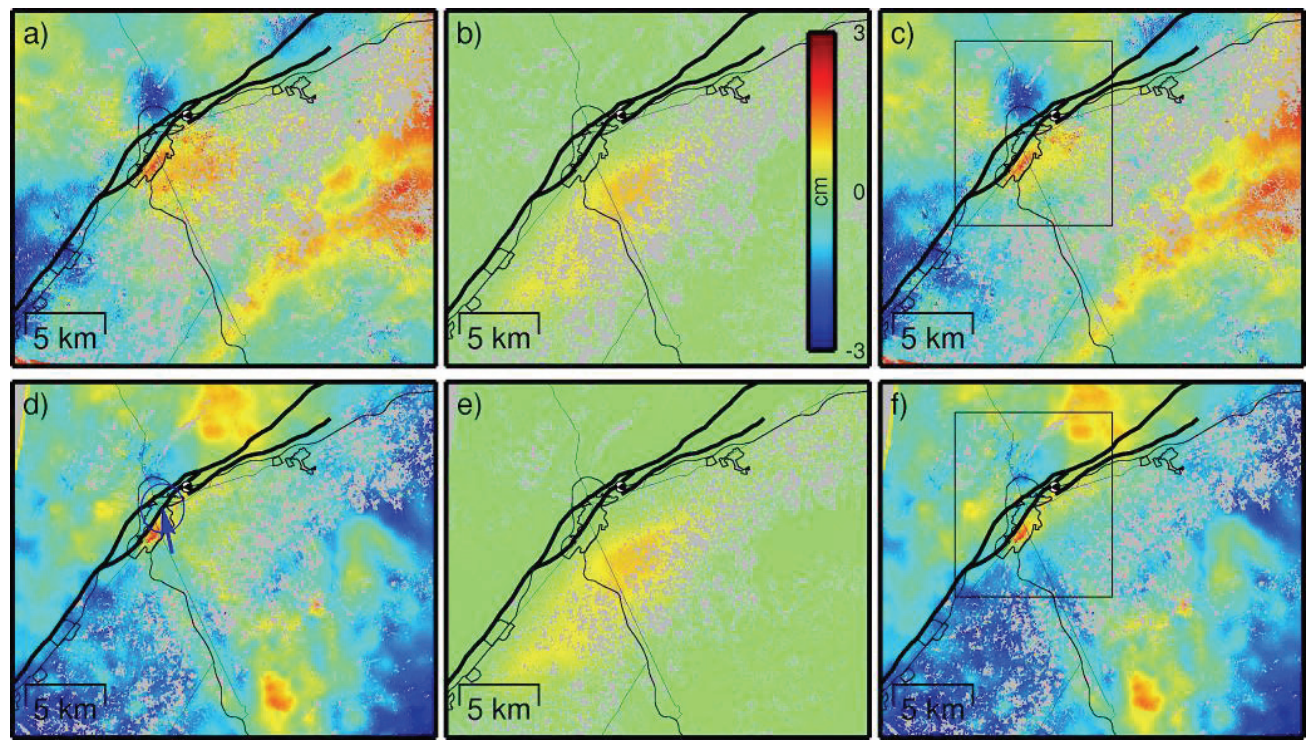

Fig. 4. a) Deformación del terreno observada entre 20110426-20110526 para el paso descendente 008 (equivalente a Fig. 3c), b) contribución modelada del hundimiento por extracción de agua (ver texto), y c) datos corregidos, diferencia entre deformación observada y hundimiento modelado. d) Deformación observada entre 20110510-20110609 para el paso descendente 209 (equivalente a Fig. 3a), e) contribución modelada del hundimiento por extracción de agua (ver texto), y f) diferencia. El área rectangular negra en c) y f) es la zona con datos que hemos usado para realizar las estimaciones del modelo de dislocación.

\subsection{Inversión no-lineal: Estimación de la geometría de la falla}

Los parámetros geométricos del modelo óptimo (localización, dimensiones, dirección y buzamiento) se obtuvieron utilizando un método de inversión no-lineal de carácter global (simulating annealing). Durante la inversión los parámetros modelo se acotaron. Los límites se seleccionaron para evitar soluciones que no sean físicamente plausibles o ambigüedades. Este tipo de soluciones no físicas se produce por ejemplo, cuando la parte superior de la falla corta por encima de la superficie del terreno, o el ángulo de buzamiento es mayor de 90 grados lo que implica que el mecanismo de fallamiento se invierta, etc. Los límites del vector de parámetros del modelo se seleccionan de forma que el intervalo de acotamiento sea lo suficientemente amplio como para explorar de forma correcta el espacio modelo (ver Fig. 5). En cada iteración del proceso de inversión, el vector de parámetros modelo inicial se perturba dentro de estos límites utilizando un generador de números aleatorios 
con probabilidad homogénea (González et al., 2010). El modelo que mejor ajusta se determina como aquel que proporciona el mínimo de la función de desajuste en un sentido mínimos cuadrados. Este proceso de inversión se repitió 1000 veces, así la dispersión de las soluciones nos permite estudiar la bondad de los resultados. Para reducir la carga computacional, los datos de alta resolución InSAR se remuestrean mediante el uso de una malla con espaciado regular usando la norma-L1 de los datos (Wessel and Smith, 1998). El muestreo espacial final es de $250 \mathrm{~m}$.

En la Tabla 2 se muestra la comparación de los resultados de la inversión de los parámetros de la fuente sísmica usando dos conjuntos de datos InSAR: con y sin corrección debida al efecto de la compactación del acuífero del Alto Guadalentín. Los resultados de ambas inversiones muestran un alto nivel de similitud que es consistente con el estilo tectónico de la región y los mecanismos focales publicados para este terremoto. Ambas estimaciones de magnitudes momento geodésicas también son similares a las magnitudes momento calculadas con los datos sísmicos, asumiendo un módulo de cizalla elástico típico para rocas de la corteza de $30 \mathrm{GPa}$. Sin embargo, el momento geodésico calculado sin corrección por la compactación del acuífero es aproximadamente un 57\% mayor que el obtenido después de aplicar la corrección, y aproximadamente un $72 \%$ mayor que el momento sísmico según el IGN (Tabla 2). Por tanto, el modelo obtenido después de aplicar la corrección por el hundimiento debido a la compactación del acuífero se compara mejor con los datos sísmicos. En consecuencia, en las siguientes secciones usamos los datos InSAR corregidos.

En la Fig. 5, se muestran gráficamente los resultados del modelo que mejor ajusta los datos observados y corregidos por hundimiento. Se muestran las funciones de densidad de probabilidad pseudo-marginales de todos los parámetros del modelo usando los 1000 modelos de mejor ajuste. La dispersión de cada parámetro permite obtener una estimación de su incertidumbre. En la Fig. 5a-f, se muestran los datos observados (Fig. 5a y d), la predicción de los desplazamientos usando la media de los parámetros del modelo (Fig. 5b y e) y sus residuos (Fig. 5c y f). Estos resultados indican que la ruptura se produjo con un deslizamiento oblicuo (inverso y lateral izquierdo) sobre una falla con dirección $\mathrm{N} 230 \mathrm{E}$ y buzamiento de $\sim 70$ grados al NE. El plano de falla es muy poco profundo, entre $1 \pm 0,3 \mathrm{~km}$ y $4 \pm 0,8 \mathrm{~km}$. Considerando la magnitud de los desplazamientos, y la simplicidad del modelo, el ajuste es relativamente bueno. Sin embargo, existen residuos significativos a lo largo de sureste de la falla estimada, a lo largo de una de las trazas al sur de la FAM en el sector de comprende la ciudad de Lorca (Fig. 5).

\subsection{Inversión lineal: Distribución de deslizamiento}

Para estudiar la distribución del deslizamiento sobre el plano de falla con mayor detalle, hemos extendido $(10 \mathrm{~km}$ x $10 \mathrm{~km})$ y discretizado la falla en segmentos de $500 \mathrm{~m}$ en longitud por $500 \mathrm{~m}$ en profundidad. La distribución de deslizamiento cosísmico se resuelve mediante el método de mínimos cuadrados con una regularización de Tikhonov. La geometría de la falla se obtiene de la inversión no lineal 
Tabla. 2. Parámetros de la fuente (ruptura de falla) estimados a partir de la inversión geodésica (C: con corrección por hundimientos por compactación de acuíferos, y O: original), en comparación con soluciones de tensor de momento sísmico I (IGN, 2011) y U (LópezComino et al, 2012). * Indica la localización del centroide. Long: Longitud, Lat: Latitud, Dep.: Profundidad; W: Anchura de la falla; L: Longitud de la falla; Str: Direccion; Us: Deslizamiento/Salto componente desgarre (lateral izquierdo); Ud: Deslizamiento/Salto componente vertical (inversa); Mo: Momento; Mw: Magnitud de momento, y RMS: Error medio cuadrático.

\begin{tabular}{|c|c|c|c|c|c|c|c|c|c|c|c|}
\hline & $\begin{array}{c}\text { Long } \\
{[\mathrm{deg} .]}\end{array}$ & $\begin{array}{c}\text { Lat } \\
{[\mathrm{deg} .]}\end{array}$ & $\begin{array}{c}\text { Dep } \\
{[\mathrm{km}]}\end{array}$ & $\begin{array}{c}\mathrm{W} \\
{[\mathrm{km}]}\end{array}$ & $\begin{array}{c}\mathrm{L} \\
{[\mathrm{km}]}\end{array}$ & $\begin{array}{c}\text { Str/Dip/Rake } \\
{[\mathrm{deg} .]}\end{array}$ & $\begin{array}{c}\text { Us } \\
{[\mathrm{cm}]}\end{array}$ & $\begin{array}{c}\text { Ud } \\
{[\mathrm{cm}]}\end{array}$ & $\begin{array}{c}\text { Mo } \\
{\left[10^{16}\right.} \\
\text { N.m] }\end{array}$ & Mw & $\begin{array}{c}\text { RMS } \\
{[\mathrm{cm}]}\end{array}$ \\
\hline $\mathrm{C}$ & $\begin{array}{c}- \\
1.6801 \\
*\end{array}$ & $\begin{array}{c}37.7023 \\
*\end{array}$ & $\begin{array}{c}1.5 \\
*\end{array}$ & 3.2 & 4.0 & $231 / 69 / 21$ & 5 & 13 & 5.36 & 5.12 & 0.16 \\
\hline $\mathrm{O}$ & $\begin{array}{c}- \\
1.6885 \\
*\end{array}$ & $\begin{array}{c}37.7036 \\
*\end{array}$ & $\begin{array}{c}4.2 \\
*\end{array}$ & 5.5 & 3.4 & $233 / 69 / 54$ & 12 & 9 & 8.42 & 5.25 & 0.12 \\
\hline $\mathrm{I}$ & - & 37.6946 & 3 & - & - & $230 / 69 / 33$ & - & - & 4.89 & 5.1 & - \\
\hline $\begin{array}{c}1.6756 \\
\mathrm{U}\end{array}$ & - & - & $4-6$ & - & - & $240 / 54 / 40$ & - & - & 6.5 & 5.2 & - \\
\hline
\end{tabular}

descrita en la subsección anterior. Sin embargo, se ha modificado ligeramente la orientación para que coincida con el patrón asimétrico observado en los interferogramas, de N230E a N225E (ver, p. e., la Fig. 4). El vector de datos de deformación observados en superficie, d, se relaciona linealmente con la distribución de deslizamiento, s, sobre la superficie de falla por

$$
\mathbf{d}=\mathrm{Gs}+\text { error, }
$$

a través del cálculo de las funciones de Green elásticas (G) (Okada, 1985). Resolvemos este problema, utilizando una función de desajuste mixta $(\phi)$, compuesta de dos términos, en primer lugar el desajuste norma euclídea o L2, y un segundo con la norma de los deslizamientos regularizados. Para el segundo término, se aplica un factor $(\kappa)$ sobre la aproximación en diferencias finitas del operador laplaciano $\left(\Delta^{2}\right)$, como un operador de suavizado. La variable $\kappa$ reduce o aumenta las heterogeneidades espaciales en la distribución de deslizamiento (Johnson et al., 2001)

$\phi(\mathbf{s}, \kappa)=\|\mathrm{Gs}-\mathbf{d}\|^{2}+\kappa^{2}\left\|\Delta^{2} \mathbf{s}\right\|^{2}, \mathbf{s} \geq 0$. 


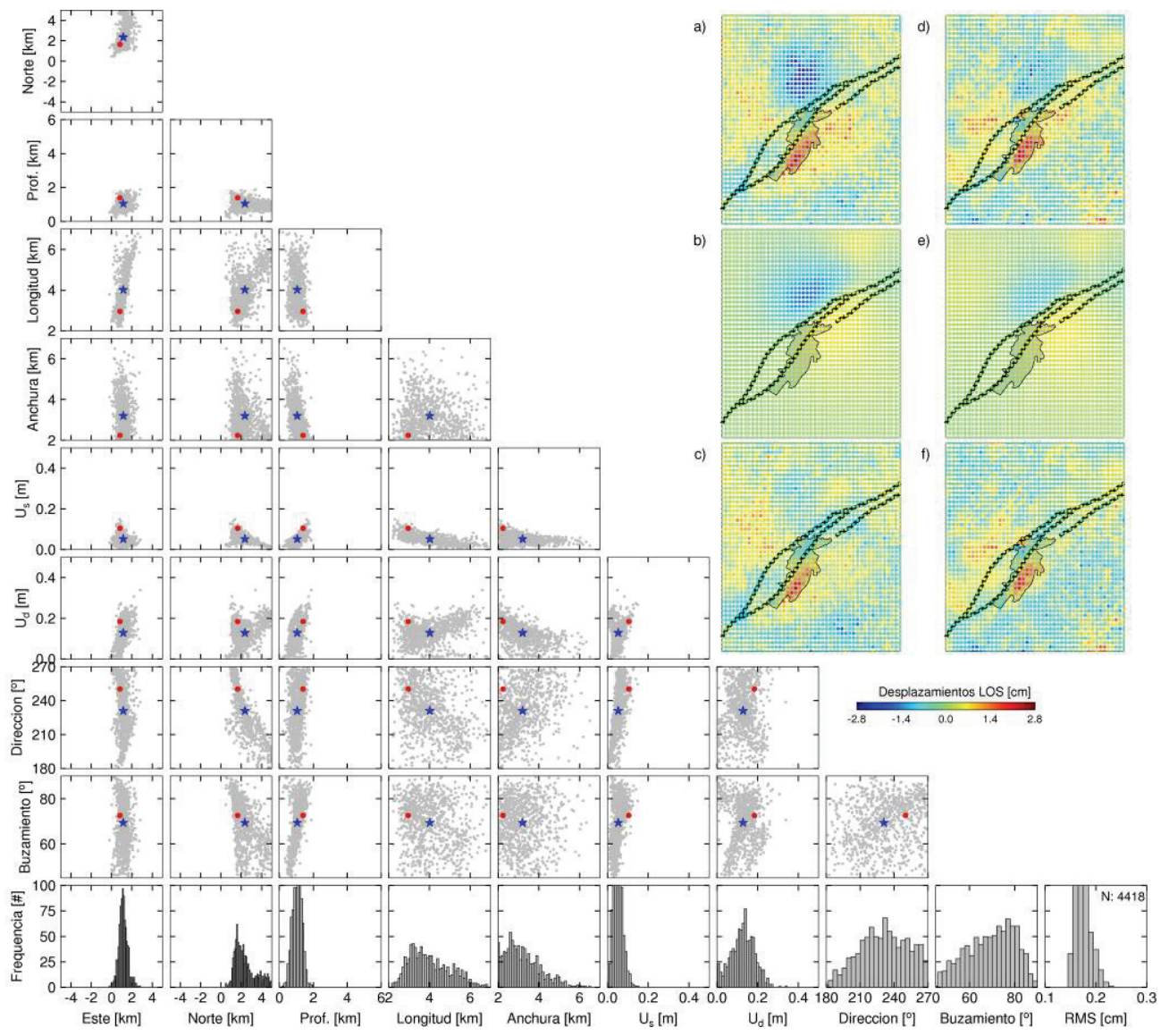

Fig. 5. La fila inferior muestra las funciones de densidad de probabilidad pseudo-marginales de todos los parámetros del modelo usando los 1000 modelos de mejor ajuste. Los gráficos de la matriz indican las funciones marginales de densidad de probabilidad 2D para cada par de parámetros. La estrella azul indica el valor medio, mientras que el punto rojo es el conjunto de parámetros con mejor ajuste. En el recuadro superior derecho, se muestra en a) y d) los resultados InSAR corregidos (paso orbital 008 y 209, respectivamente), en b) y e) predicción del desplazamiento del modelo promedio (paso orbital 008 y 209, respectivamente), y en c) y f) los residuos (paso orbital 008 y 209, respectivamente). Nota: Las coordenadas Este y Norte están en un marco de referencia local de coordenadas cartesianas con proyección centrada en -1,6967; 37.6695 (longitud y latitud). 


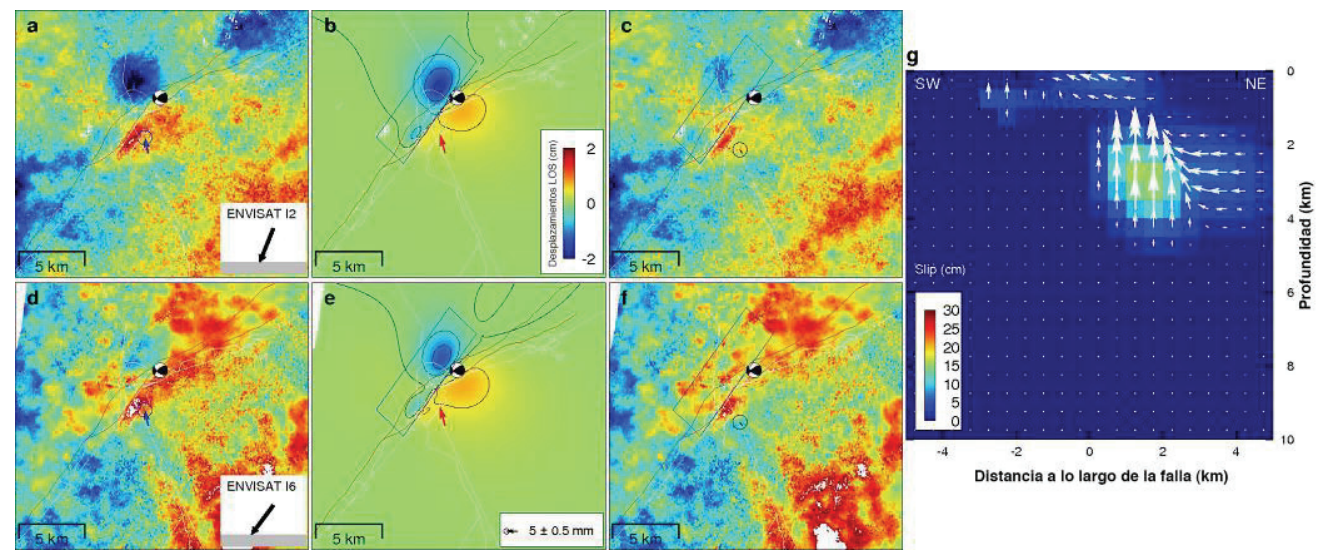

Fig. 6. Paneles a) y d) muestran los datos observados (paso orbital 008 y 209, respectivamente); b) y e) muestran las predicciones del modelo (paso orbital 008 y 209, respectivamente); c) y f) muestran los residuos (paso orbital 008 y 209, respectivamente), y en el panel g) se muestra el modelo de deslizamiento de falla cosísmico distribuido sobre un plano de falla que buza $\left(70^{\circ} \mathrm{NE}\right)$. El factor de suavizado preferido es $\kappa=2$. La proyección en superficie del plano de falla se muestra como un rectángulo azul en los paneles b, c, e y f. Las fallas cartografiadas y el mecanismo focal del IGN están representados también. El modelo de deslizamiento cosísmico en g) se muestra con vista desde el sudeste.

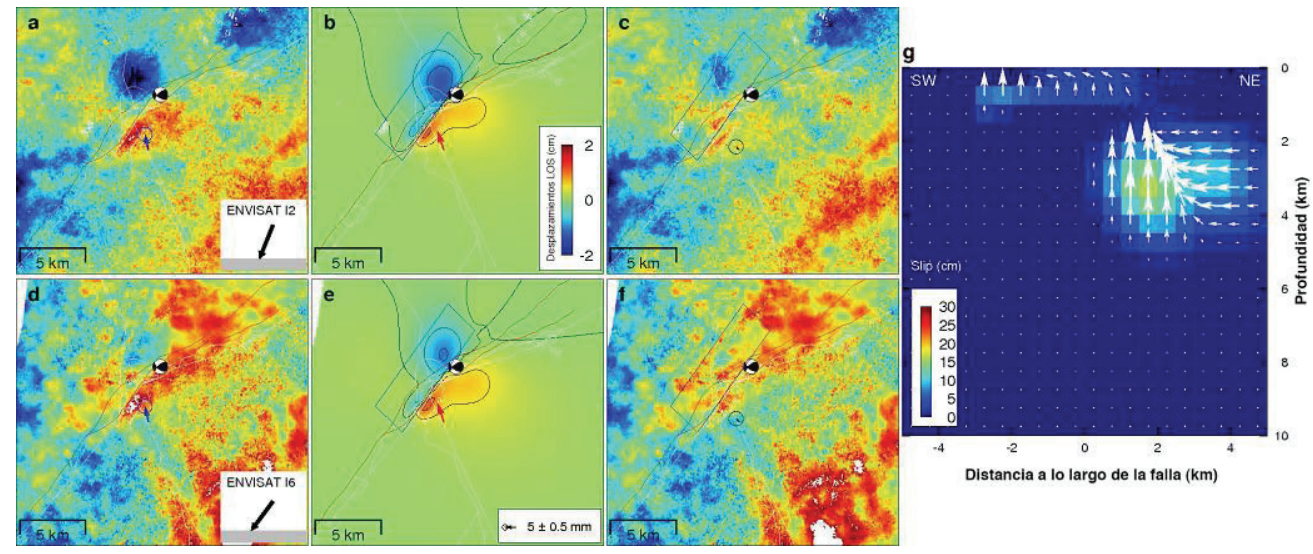

Fig. 7. Paneles a) y d) muestran los datos observados (paso orbital 008 y 209, respectivamente); b) y e) muestran las predicciones del modelo (paso orbital 008 y 209, respectivamente); c) y f) muestran los residuos (paso orbital 008 y 209, respectivamente), y en el panel g) se muestra el modelo de deslizamiento de falla cosísmico distribuido sobre un plano de falla que buza $\left(70^{\circ} \mathrm{NE}\right)$ con un pequeño segmento vertical de $1-\mathrm{km}$ cerca de superficie. El factor de suavizado preferido es $\kappa=2$. Símbolos iguales que en Fig. 6. El modelo de desli- 
zamiento cosísmico en g) se muestra con vista desde el sudeste. Nótese el claro cambio en la deformación modelada en b) y e), que reduce los residuos en c) y f) con respecto a la Fig. 6.

El factor de suavizado óptimo o preferible se determina utilizando una curva de equilibrio obtenida con un valor de compromiso entre el desajuste de datos (normaL2) y la cantidad de suavizado en la distribución de deslizamiento (Bürgmann et al., 2002). Sin embargo, este parámetro de suavizado, $\kappa$, suele estar muy poco constreñido. Para obtener un valor óptimo hemos utilizado el método de la curva L, porque en circunstancias ideales, la curva L muestra un claro cambio de pendiente en el valor óptimo en una escala log-log (Asters et al., 2005). En la Fig. 6, se muestra el modelo de deslizamiento de falla distribuido cosísmico con mejor ajuste usando de forma conjunta dos datos InSAR y los desplazamientos cosísmicos GPS. El modelo suavizado preferido $(\kappa=2)$ permite dos segmentos de falla con deslizamiento, una zona principal, con el movimiento oblicuo (inverso y lateral izquierdo, con $\sim 15-20$ $\mathrm{cm}$ máximo) debajo del segmento al norte de Lorca (La Tercia-FAM), a profundidades que van de 2 a $5 \mathrm{~km}$. Y una zona mucho más superficial y con un deslizamiento más pequeño en magnitud, con movimiento lateral izquierdo que progresa hacia inverso puro debajo de la ciudad a lo largo del segmento de sur de FAM en Lorca. Este deslizamiento alcanza hasta $\sim 5 \mathrm{~cm}$ (Fig. 6g). Sin embargo, este modelo también muestra residuos significativos en la ciudad de Lorca, al sureste de la traza de FAM.

A partir de la geología de superficie, sabemos que la FAM está compuesta por varias subfallas cerca de superficie y han sido identificadas con buzamiento vertical o ligeramente hacia el sureste, en el segmento de Totana $(\sim 15 \mathrm{~km}$ al nordeste) a Lorca (Masana et al., 2004; IGN, 2011; Martínez-Díaz, 2002). En consecuencia, de forma tentativa hemos incluido en la geometría del plano de falla un pequeño segmento de falla vertical desde la superficie hasta una profundidad de $1 \mathrm{~km}$. En la Fig. 7, se observa una mejora en el ajuste del modelo a los datos en esta zona, sin cambios significativo en otras áreas. Este resultado indica que, aunque no esté perfectamente constreñido, un segmento con buzamiento vertical cerca de superficie mejora el ajuste entre modelo y datos de deformación superficiales observadas (Fig. 7). Por último, la introducción de un pequeño segmento de falla vertical no modifica el patrón de deslizamiento observado y sólo cambia ligeramente la cantidad de movimiento cerca de superficie (Fig. 7g).

\section{Modelo de variación de esfuerzos cosísmicos}

En las últimas dos décadas, el uso de los cambios de esfuerzos estáticos (o dinámicos) de Coulomb inducidos por terremotos ha sido aplicado con éxito para estudiar la interacción entre fallas y la evolución de la sismicidad (King et al., 1994). El método se basa en la existencia de fallas preexistentes, que se comportan como una interfaz de rozamiento de las superficies de separación de dos bloques de la corteza terrestre. La superficie de rozamiento se caracteriza por una ley de resistencia o de Amonton, que relaciona la resistencia al corte de la falla y la tensión normal que actúa sobre el plano (Lockner and Beeler, 2002). De forma más general, un evento 
de ruptura dinámica (terremoto) se produce cuando la resistencia al corte de la falla es más pequeña que el esfuerzo de cizalla que actúa sobre el plano. Esta condición se conoce como el criterio de fallamiento de Coulomb. Este criterio se puede escribir como,

$$
|\tau|=\mathrm{c}+\mu_{\mathrm{i}} \sigma_{\mathrm{n}},
$$

donde $\tau$ y $\sigma_{\mathrm{n}}$ son los esfuerzos de cizalla y normales que actúan sobre la superficie de la falla, c es la cohesión, y el $\mu_{\mathrm{i}}$ es el coeficiente de rozamiento interno. Por lo tanto, el movimiento de la falla se inicia cuando el cambio de esfuerzos o función de fallamiento de coulomb $(\triangle \mathrm{CFF})$, supera un determinado umbral. Actualmente, el valor del umbral no ha sido bien delimitado y es un tema de intenso debate (Felzer and Brodsky, 2005; Parsons and Velasco, 2011).

En este caso, se utiliza el modelo de distribución de deslizamiento cosísmico estimado para calcular el cambio de esfuerzos elásticos inducidos en la corteza alrededor de la zona hipocentral debido al terremoto de Lorca. Se usa el código Coulomb 3. Este programa se basa en una solución analítica de los desplazamientos y esfuerzos elásticos internos producidos por una dislocación rectangular (Okada, 1992). Se asume un coeficiente de rozamiento de 0,4. El coeficiente de Skempton, que se aplica a las tensiones normales, para tener en cuenta las condiciones en régimen de drenaje en las rocas corticales es de 0,5. Para estudiar de manera más realista la magnitud del cambio de esfuerzos se debe tener en cuenta el tensor de esfuerzos regionales (King et al., 1994). El campo de esfuerzos regional (orientación y magnitud) es un parámetro difícil de estimar, pero una aproximación de primer orden se puede obtener usando la base de datos de Global Stress Map Project. En concreto, el $\sigma 1$ en esta región es sub-horizontal y orientado NNW-SSE $\left(\sim 160^{\circ}-175^{\circ}\right)$. Esta orientación está en acuerdo con inversiones de mecanismos focales de terremotos (Palano et al., 2012). Desafortunadamente, los valores de magnitud no están disponibles. Por ello se realizó una estimación a partir del campo de velocidades de deformación finita estimadas con datos GPS. Primero se estimó la velocidad y su error utilizando el polígono formado por las cuatro estaciones más cercanas (CRTG, HUOV, MURC y CRVC), Fig. 2a. Luego, suponiendo que la corteza es un medio elástico lineal e isótropo, usando la Ley de Hooke (Heitz, 1980), calculamos la magnitud de los esfuerzos 3D. Para el cálculo, se usan valores de 30 GPa y 0,25 para el módulo de cizalla y la razón de Poisson, respectivamente, de acuerdo con los valores utilizados previamente para el modelado elástico. El tensor de esfuerzos 3D se muestra en la Tabla 3.

En la Fig. 8, se muestran cortes horizontales a diferentes profundidades $(3,4$ y 5 $\mathrm{km}$ ) del modelo de cambios de esfuerzos resultante del movimiento de falla cosísmico. Se han analizando planos de falla con diferentes regímenes (fallamiento normal, desgarre e inverso) y orientados óptimamente con respecto a las campo de esfuerzos regional. Debido a los cambios en el cabeceo y la magnitud de los deslizamientos sobre el plano de la ruptura, el modelo de cambio de esfuerzos representa un patrón complejo con áreas de aumento y disminución de $\Delta$ CFF. Para el caso del 
fallamiento normal, los cambios positivos se concentra sobre todo por encima del plano de falla (Fig. 8a-c), puesto que los esfuerzos extensionales debido al movimiento (principalmente inverso) se transfieren al bloque de techo. En el caso de la existencia de fallas de desgarre, se prevé que se activen a lo largo de un patrón con forma de mariposa (negativa-positiva) con predominancia en la profundidad del deslizamiento máximo, $4 \mathrm{~km}$ (Fig. 8e), así como para la región superficial al suroeste del epicentro (Fig. 8c). Por último, según el modelo, las fallas inversas se activarían principalmente a lo largo de las secciones más profundas (Fig. 8h y 8i).

Tabla 3. Valores del campo de esfuerzos calculado con los datos geodésicos.

\begin{tabular}{|c|r|r|r|}
\hline $\begin{array}{c}\text { Eje de } \\
\text { esfuerzos }\end{array}$ & Dirección & Buzamiento & $\begin{array}{c}\text { Magnitud } \\
(\mathrm{MPa})\end{array}$ \\
\hline$\sigma 1$ & 336.5 & 85.2 & $3.4 \cdot 10^{-1}$ \\
\hline$\sigma 2$ & 72.5 & 0.5 & $-2.2 \cdot 10^{-3}$ \\
\hline$\sigma 3$ & 162.5 & 4.8 & $-8.7 \cdot 10^{-2}$ \\
\hline
\end{tabular}

\section{Discusión y conclusiones}

Los primeros análisis de los antecedentes geológicos, datos sismológicos y los mecanismos focales tentativamente atribuyen el terremoto de Lorca del 11 de mayo $2011 \mathrm{Mw}=5.1$ (SE, España) a la FAM. A pesar de que la FAM es la fuente sísmica más plausible en el área, los informes preliminares en los primeros meses no aportan datos concluyentes que atribuyeran el terremoto a la FAM (Martínez-Díaz et al., 2011; Vissers and Meijninger, 2011). Los análisis de datos sismológicos fueron los que proporcionaron las primeras evidencias de que la FAM fue la falla responsable del terremoto de Lorca (Rueda et al., 2011; López-Comino et al., 2012). Si bien nuestros primeros resultados basados en observaciones InSAR ya indicaban esa fuente (Fernández et al., 2011; González et al., 2011). Rueda et al. (2011) y LópezComino et al. (2012) discuten ampliamente la directividad de la energía sísmica.

Ambos estudios suministran soluciones actualizadas del tensor momento de la ruptura, y coinciden en apreciar un efecto de direccionalidad clara de la energía sísmica radiada, que puede explicar el alto valor de aceleración del terreno registrado en la ciudad de Lorca $(\sim 0,4 \mathrm{~g})$. Sin embargo, hay algunas incertidumbres acerca de si la ruptura fue unidireccional (Rueda et al., 2011) o asimétrica bilateral (LópezComino et al., 2012). Por otra parte, Rueda et al. (2011) calculan un modelo de distribución de deslizamiento a lo largo de la FAM, que alcanza un máximo de $\sim 17$ $\mathrm{cm}$, con una velocidad de ruptura de $3.1 \mathrm{~km} / \mathrm{s}$, mientras que López-Comino et al. (2012) estiman un deslizamiento promedio de $\sim 14 \mathrm{~cm}$ en $3.4 \mathrm{~km}$ de longitud de la ruptura y con una velocidad de ruptura de $2,4 \mathrm{~km} / \mathrm{s}$. Desafortunadamente, usando sólo los datos geodésicos descritos no podemos validar los efectos de la ruptura o la direccionalidad. Sin embargo, nuestros resultados coinciden con los datos sísmicos 
en que la ruptura se produjo a lo largo de la FAM, y también en la magnitud del deslizamiento máximo $(\sim 14-17 \mathrm{~cm})$.

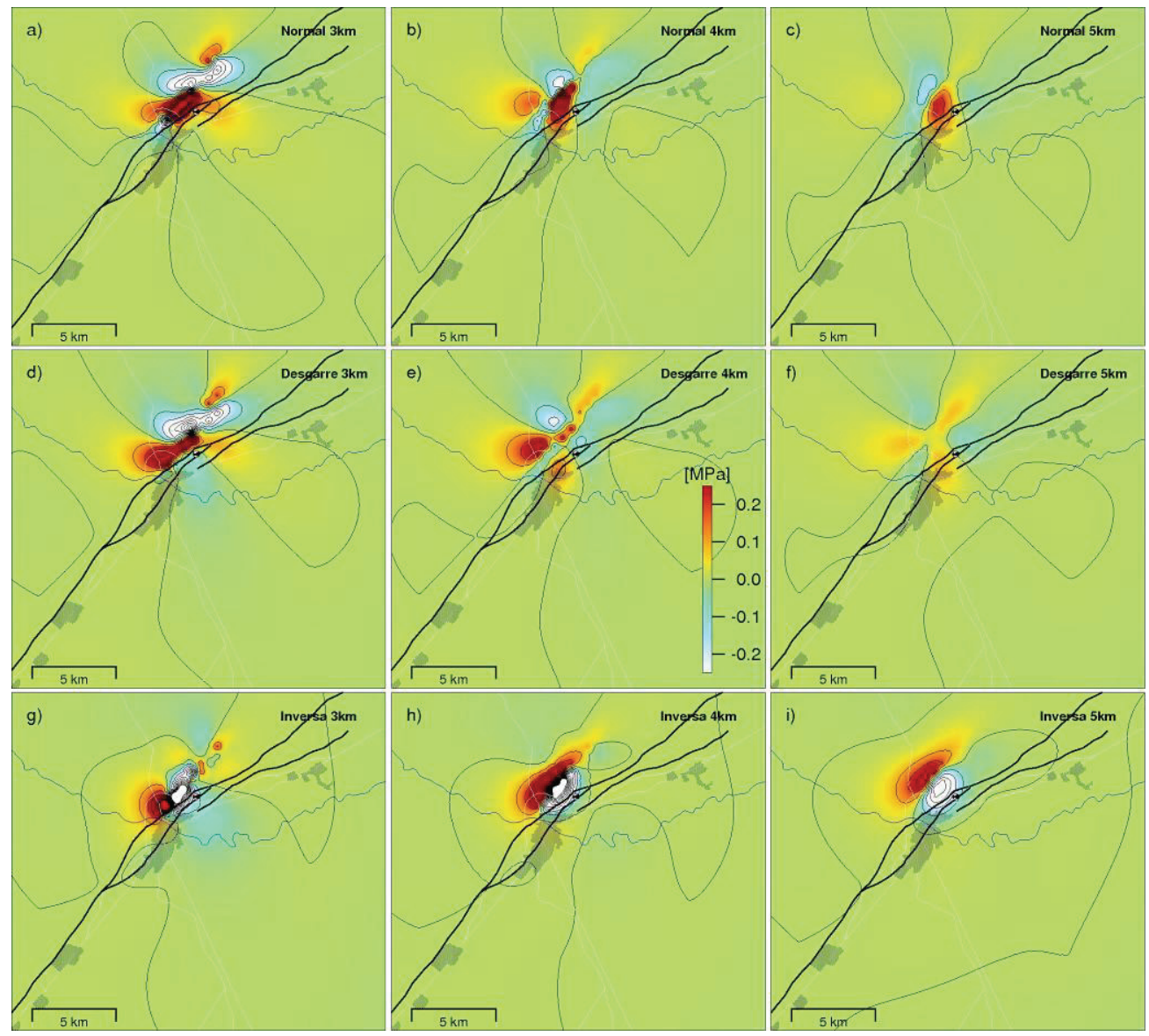

Fig. 8. Mapas (cortes) a 3, 4 y $5 \mathrm{~km}$ de profundidad (paneles de la izquierda, centro y derecha) del $\triangle \mathrm{CFF}$ con líneas de contorno que indican niveles de $\Delta \mathrm{CFF}=0,1 \mathrm{MPa}$ para fallas normales orientadas de forma óptima $(\mathbf{a}, \mathbf{b}, \mathbf{c})$, fallas de desgarre orientadas de forma óptima (d, e, f), y fallas inversas orientadas de forma óptima $(\mathbf{g}, \mathbf{h}, \mathbf{i})$. Las réplicas relocalizadas (polígono de color rojo en la Figura. 1b) coinciden con las áreas de cambio positivo $\triangle \mathrm{CFF}$ a poca profundidad $(3-4 \mathrm{~km})$ para fallas de desgarre y para profundidad $(4-5 \mathrm{~km})$ para fallas inversas. La escala de color está saturada para valores de $\Delta \mathrm{CFF},-0,25$ a $0,25 \mathrm{MPa}$, valores positivos hacia el rojo. 
En los reconocimientos de campo no se encontró ninguna evidencia clara de ruptura de la falla en superficie (Martínez-Díaz et al., 2011). Sin embargo, nuestro modelo geodésico requiere de una zona de deslizamiento de poca magnitud $(\sim 5 \mathrm{~cm})$, cerca o en superficie, y justo al norte de la ciudad de Lorca. Esta zona coincide aproximadamente con un muro de contención dañado en las márgenes de la rambla del rio Guadalentín a su paso por Lorca (Fig. 3.1 y 3.2 en Martínez-Díaz et al., 2011). Esto podría ser una evidencia de la ruptura de la falla muy cerca de la superficie, tal vez incluso a menos de $500 \mathrm{~m}$ (que es la resolución espacial de nuestro modelo de falla). De hecho, en nuestro modelo de deslizamiento distribuido, este es el único lugar para el que se predice ruptura en superficie. Mientras que el resto del modelo tiene un mayor deslizamiento en profundidad $(2-5 \mathrm{~km})$ a lo largo de una porción a $5 \mathrm{~km}$ del segmento de La Tercia-FAM, y un deslizamiento pequeño bajo la ciudad de Lorca que no se propagan hasta superficie (Fig. 7g). Esta zona marca también el cambio de rumbo entre los segmentos de La Tercia-FAM y Lorca-FAM, de $\sim 235 \mathrm{E}$ a $\sim$ N225E. El cambio en el rumbo de la falla entre estos segmentos podría haber tenido un efecto en el reparto del deslizamiento cosísmico en nuestro modelo.

Previamente, hemos estimado el campo de velocidad de deformación finita (Sección 2.1) usando datos GPS. Este campo es compatible con los mecanismos de falla en la región, que muestran fallamiento de inverso a desgarre, ya que los ejes principales del campo de velocidad de deformación finita muestran un acortamiento uniaxial (en la falla de Crevillente) y son de magnitud similar (a lo largo de la FAM) de acuerdo con las soluciones de mecanismos focales disponibles para la región. Este resultado también está de acuerdo con la comparación entre el mecanismo focal y la geología de la superficie (Visser y Meijninger, 2011). Una comparación entre el fallamiento óptimo, según el campo de velocidad de deformación finita, las soluciones de mecanismos focales estimadas, y nuestros modelos de deslizamientos en la falla (homogéneo y distribuido), muestra un acuerdo sobre una tectónica de compresión con un cierto movimiento lateral izquierdo a lo largo de la FAM (Martínez-Díaz et al., 2002; Masana et al., 2004). Estos resultados además confirman que la estructura geológica multi-segmentada FAM está favorablemente orientada con el campo de esfuerzos presente y está acumulando deformación elástica. Esta falla representa una fuente sísmica con potencial para generar grandes terremotos, si se rompe un segmento entero en un único evento, o múltiples segmentos en cascada. Sin embargo, esta segunda hipótesis parece más improbable, ya que la ruptura dinámica del reciente terremoto de Lorca (segmento de La Tercia-FAM) se detuvo en profundidad y sólo se propagó de forma limitada en el segmento de Lorca cerca de superficie. En el futuro se deberán desarrollar más investigaciones para entender las condiciones bajo las cuales podría propagarse la ruptura de un segmento a otro.

A tenor de los resultados obtenidos, podemos concluir que:

- El terremoto de Lorca del 11 de mayo 2011 se produjo a lo largo de la falla de Alhama de Murcia. 
- La ruptura comenzó en el segmento de La Tercia-FAM y progreso hacia el sur y hacia la superficie (segmento de Lorca-FAM), como movimiento inverso y lateral izquierdo (con un deslizamiento máximo de $\sim 20 \mathrm{~cm}$ ).

- La magnitud de deslizamiento cosísmico es consistente con los límites superiores previstos de déficit de deslizamiento máximo calculado con datos paleosísmicos, incluso en el caso de que el evento 2011 rompiese el mismo segmento que el evento de 1818.

- La variación de esfuerzos cosísmica calculada considerando el campo de esfuerzos regional puede explicar la secuencia de réplicas para el caso de deslizamiento que varía de inverso a desgarre a lo largo de la falla de Alhama de Murcia o en fallas subparalelas.

\section{Agradecimientos}

KFT y PJG agradecen la financiación de una Ontario Early Research Award, y una NSERC Discovery Grant. PJG agradece también la Banting Postdoctoral Fellowship del Gobierno de Canadá. La investigación de JF se ha realizado en el marco del proyecto de investigación GEOSIR (AYA2010 17448). Este trabajo se ha desarrollado en el marco del Campus de Excelencia Internacional de Moncloa (UCM-UPM, CSIC). Todas las figuras se han realizado con el programa de código abierto GMT (Wessel and Smith, 1998).

\section{Referencias bibliográficas}

ASTER, R., BORCHER, B., \& THURBER C.H. (2005). Parameter Estimation and Inverse Problems. Academic Press, International Geophysics Series, $320 \mathrm{p}$.

BEAVAN, J. \& HAINES, J. (2001). Contemporary horizontal velocity and strain rate fields of the Pacific-Australian plate boundary zone through New Zealand. $J$. Geophys. Res., vol. 106, 741-770, doi:10.1029/2000JB900302.

BÜRGMANN, R. et al., (2002). Deformation during the 12 November 1999 Düzce, Turkey, earthquake from GPS and InSAR data. Bull. Seismol. Soc. Amer., vol. 92, 161-171.

CHEN C. W. \& ZEBKER, H. A. (2002). Phase unwrapping for large SAR interferograms: Statistical segmentation and generalized network models. IEEE Transactions on Geoscience and Remote Sensing, vol. 40, 1709-1719.

FELZER, K. R. \& BRODSKY, E. E. (2005). Testing the stress shadow hypothesis. J. Geophys. Res., vol. 110, B05S09, doi:10.1029/2004JB003277.

FERNÁNDEZ J., GONZÁLEZ, P. J. \& TIAMPO, K. F. (2011). Interferometria radar y deformaciones cosísmicas, presented at Iberian seismic hazard workshop. A Cenozoic tectonics perspective, Madrid, 30 de Junio.

GONZÁLEZ P. J., TIAMPO, K. F., CAMACHO, A. G. \& FERNÁNDEZ, J. (2010). Shallow flank deformation at Cumbre Vieja volcano (Canary Islands): Implications on the stability of steep-sided volcano flanks at oceanic islands. Earth Planet. Sci. Lett., vol. 297 (3-4), 545-557, doi:10.1016/j.epsl.2010.07.006.

GONZÁlEZ P. J., TIAMPO, K. F., PALANO, M., CANNAVÒ, F. \& FERNÁNDEZ, J. (2011). Geodetically derived fault slip distribution model for 
the May, 11th 2011 Lorca earthquake (SE, Spain), Abstract G23A-0842 presented at 2011 Fall meeting, $A G U$, San Francisco, Calif., 5-9 Dec.

GONZÁLEZ P. J. \& FERNÁNDEZ, J. (2011a). Error estimation in multitemporal InSAR deformation time series, with application to Lanzarote, Canary Islands. $J$. Geophys. Res., vol. 116, B10404, doi:10.1029/2011JB008412.

GONZÁLEZ P. J. \& FERNÁNDEZ, J. (2011b). Drought-driven transient aquifer compaction imaged using multitemporal satellite radar interferometry. Geology, vol. 39(6), 551-554, doi:10.1130/G31900.1.

HEITZ, S. (1980). Mechanik fester Körper, Dümmler, Bonn.

HERRING T. A., KING, R. W. \& MCCLUSKY S. C. (2009). Introduction to GAMIT/GLOBK, Release 10.4. Massachusetts Institute of Technology, Cambridge, MA. 48 pp.

JOHNSON, K. M, HSU, Y. J., SEGALL, P. \& YU S. B. (2001). Fault geometry and slip distribution of the 1999 Chi-Chi, Taiwan earthquake imaged from inversion of GPS data. Geophys. Res. Lett., vol. 28, 11, 2285-2288.

KAMPES B., HANSSEN, R. \& PERSKI, Z. (2003). Radar interferometry with public domain tools. Proceedings of the 2nd ESA Fringe 2003 workshop, ESAESRIN, Frascati, Italy.

KING, R. \& BOCK, Y. (2004). Documentation for the GAMIT GPS Analysis Software, Release 10.2. Massachusetts Institute of Technology, Cambridge, MA, and Scripps Institute of Oceanography, La Jolla, CA.

KING, G. C. P., STEIN, R. S. \& LIN, J. (1994). Static stress changes and the triggering of earthquakes. Bull. Seismol. Soc. Amer., vol. 84 (3), 935-953.

LOCKNER, D. A. \& BEELER, N. M. (2002). Rock failure and earthquakes. In: International Handbook of Earthquake and Engineering Seismology, Part A, Eds: LEE, W.K, KANAMORI H., JENNINGS P.C. \& KISSLINGER, C., Academic Press.

LÓPEZ-COMINO J. A., MANCILLA, F., MORALES J. \& STICH, D. (2012). Rupture directivity of the 2011, Mw 5.2 Lorca earthquake (Spain). Geophys. Res. Lett., vol. 39, L03301, doi:10.1029/2011GL050498.

MARTÍNEZ-DÍAZ, J. J. (2002). Stress field variety related to fault interaction in a reverse oblique-slip fault: the Alhama de Murcia fault, Betic cordillera, Spain. Tectonophysics, vol. 356, 291-305.

MARTIINEZ-DÍAZ, J. J., MASANA, E., HERNÁNDEZ-ENRILE, J. L. \& SANTANACH, P. (2003). Effects of the paleoseismic activity of an oblique slip fault on the morphology and sedimentology of an alluvial fan (Alhama de Murcia fault, Betic Cordillera-Spain). Annals of Geophysics, vol. 46(5), 775-793.

MARTÍNEZ-DÍAZ, J. J., et al., (2011). Informe geológico preliminar del terremoto de Lorca del 11 de Mayo del año 2011, 5.1 Mw. http://www.iberfault.org/docs/Informe Geologico Preliminar Terremoto_Lorca 11 Mayo 2011.pdf, [último acceso: 2012/04/16].

MASANA, E., MARTÍNEZ-DÍAZ, J. J., HERNÁNDEZ-ENRILE, J. L. \& SANTANACH, P. (2004). The Alhama de Murcia fault (SE Spain), a seismogenic fault in a diffuse plate boundary: Seismotectonic implications for the 
Ibero-Magrebian region. J. Geophys. Res., vol. 109, B01301, doi:10.1029/2002JB002359.

MEZCUA, J., HERRAÍZ, M. \& BUFORN E. (1984). Study of the 6 June 1977 Lorca (Spain) earthquake and its aftershock sequence. Bull. Seismol. Soc. Amer., vol. 74, 167- 179 .

IGN (2011). Informe del sismo de Lorca del 11 de mayo de 2011. http://www.ign.es/ign/resources/sismologia/Lorca.pdf [último acceso: 2012/04/16].

OKADA, Y. (1985). Surface deformation due to shear and tensile faults in a halfspace. Bull. Seismol. Soc. Amer., vol. 75, 1135-1154.

OKADA, Y. (1992). Internal deformation due to shear and tensile faults in a halfspace. Bull. Seismol. Soc. Amer., 82 (2), 1018-1040.

PALANO, M., CANNAVÒ, F., FERRANTI L., MATTIA M. \& MAZZELLA, M. E. (2011). Strain and stress fields in the Southern Apennines (Italy) constrained by geodetic, seismological and borehole data. Geophys. J. Int., vol. 187, 12701282, doi: 10.1111/j.1365-246X.2011.05234.x.

PALANO, M., GONZÁLEZ P. J. \& FERNÁNDEZ, J. (2012). Strain and stress fields along the Gibraltar Orogenic Arc: constrains on active geodynamics. Gondwana Research., doi:10.1016/j.gr.2012.05.021.

PARSONS, T., \& VELASCO, A. A. (2011). Absence of remotely triggered large earthquakes beyond the main shock region. Nature Geoscience, vol. 4, p. 312316, doi:10.1038/ngeo1110.

ROSEN, P. A., HENLEY, S., PELTZER, G. \& SIMONS, M. (2004). Updated Repeat Orbit Interferometry Package Released. Eos Trans. AGU, vol. 85(5), 47.

RUEDA, J., MEZCUA, J. \& GARCÍA BLANCO, R. M. (2011). Directivity effects of the May 11, 2011 Lorca (Spain) $\mathrm{Mw}=5.1$ earthquake. Abstract S53B-2277 presented at 2011 Fall meeting, $A G U$, San Francisco, Calif., 5-9 Dec.

VISSERS, R. L. M. \& MEIJNINGER, B. M. L. (2011). The 11 May 2011 earthquake at Lorca (SE Spain) viewed in a structural-tectonic context. Solid Earth, vol. 2, 199-204, doi:10.5194/se-2-199-2011.

WESSEL, P. \& SMITH, W. H. F. (1998). New, improved version of the Generic Mapping Tools released. EOS Trans. AGU, vol. 79, 579. 